\title{
In situ synthesis of biomolecule encapsulated gold-cross-linked poly(ethylene glycol) nanocomposite as biosensing platform: A model study
}

\author{
Dilek Odaci ${ }^{\text {a }}$ Muhammet U. Kahveci ${ }^{\mathrm{b}}$, Elif L. Sahkulubey ${ }^{\mathrm{b}}$, Caglar Ozdemir ${ }^{\mathrm{a}}$, \\ Tamer Uyar ${ }^{c}$, Suna Timur ${ }^{\mathrm{a}, *}$, Yusuf Yagci ${ }^{\mathrm{b}, *}$ \\ a Ege University, Faculty of Science, Biochemistry Department, Bornova, 35100, Izmir, Turkey \\ b Istanbul Technical University, Faculty of Science and Letters, Department of Chemistry, Maslak, 34469, Istanbul, Turkey \\ c UNAM-Institute of Materials Science E' Nanotechnology, Bilkent University, 06800, Ankara, Turkey
}

\section{A R T I C L E I N F O}

\section{Article history:}

Received 21 March 2010

Received in revised form 29 April 2010

Accepted 2 May 2010

Available online 10 May 2010

\section{Keywords:}

Biosensor

Bionanocomposite

Hydrogel

Gold nanoparticles

Photopolymerization

\begin{abstract}
A B S T R A C T
In situ synthesis of poly(ethylene glycol) (PEG) hydrogels containing gold nanoparticles (AuNPs) and glucose oxidase (GOx) enzyme by photo-induced electron transfer process was reported here and applied in electrochemical glucose biosensing as the model system. Newly designed bionanocomposite matrix by simple one-step fabrication offered a good contact between the active site of the enzyme and AuNPs inside the network that caused the promotion in the electron transfer properties that was evidenced by cyclic voltammetry as well as higher amperometric biosensing responses in comparing with response signals obtained from the matrix without AuNPs. As well as some parameters important in the optimization studies such as optimum pH, enzyme loading and AuNP amount, the analytical characteristics of the biosensor (AuNP/GOx) were examined by the monitoring of chronoamperometric response due to the oxygen consumption through the enzymatic reaction at $-0.7 \mathrm{~V}$ under optimized conditions at sodium acetate buffer ( $50 \mathrm{mM}, \mathrm{pH} 4.0$ ) and the linear graph was obtained in the range of $0.1-1.0 \mathrm{mM}$ glucose. The detection limit (LOD) of the biosensor was calculated as $0.06 \mathrm{mM}$ by using the signal to noise ratio of 3 . Moreover, the presence of AuNPs was visualized by TEM. Finally, the biosensor was applied for glucose analysis for some beverages and obtained data were compared with HPLC as the reference method to test the possible matrix effect due to the nature of the samples.
\end{abstract}

(c) 2010 Elsevier B.V. All rights reserved.

\section{Introduction}

Nano- and biotechnologies offer opportunities to design complex and optimized soft structures with synergistic properties. The possibilities to control chemical and physical properties via the design of 3D gel structures provide a powerful strategy for incorporation of versatility into engineering gels from the nanometer scale. Generally, nanocomposite polymer hydrogels may be defined as cross-linked polymer networks swollen with water in the presence of nanostructures or nanoparticles which add unique physical properties to these architectures such as responsiveness to mechanical, optical, thermal, magnetic, electric stimulation, etc. All these unique properties enable these matrices to apply in the electronics, optics, sensors, actuators and microfluidics systems as well as catalysis, separation devices, drug delivery, and many other biotechnological areas [1]. Methods for the immobilization of the biomolecules in different matrices [2-7] are continuously being developed, and such biocomposites have important applications in chemical and biological

\footnotetext{
* Corresponding authors. Timur is to be contacted at Tel./fax: +90 2323438624 . Yagci, Tel.: +90212285 324; fax: + 902122856386 .

E-mail addresses: suna.timur@ege.edu.tr (S. Timur), yusuf@itu.edu.tr (Y. Yagci).
}

analyses [8-12]. On the other hand, considerable attention has been devoted to immobilization of enzymes on electrode surface in relation to the biosensor design and biotechnological processes [13-20]. The ideal enzyme immobilization process should be cheap, quick and enzyme friendly, should result in high loading factors, and should be applicable to various biomolecules. With regard to the matrix used for enzyme immobilization, use of biocompatible and inert matrices is one of the most important requirements; for instance it should not interfere with the native structure of the enzyme and thereby compromise its biological activity [21].

Hybrid materials can be obtained by combining metal based nanoparticles such as Au and Ag with polymer hydrogels so that the properties of the nanoparticle such as improved electrical conductivity, response to optical stimuli, improved antimicrobial properties, etc. are added to the gel [1]. The large interest in nanostructures is due to their several applications in different areas including biomedical sciences, electronics, optics, energy storage, and electrochemistry [22]. Various nanoparticles are used in the design of electrochemical biosensors in recent publications in which electrodes were successfully modified with nanoparticles and biomolecules, and these combinations are of considerable interest in the fields of biotechnology and bioanalytical chemistry [11,23-25]. 
Among various nanostructures, gold nanoparticles (AuNP) can play an important role in improving the biosensor performance due to their large effective surface area and excellent biocompatibility [26-28].

Quite recently, an elegant method for synthesis of polymeric materials containing metal nanoparticles has been developed in our laboratory [29-33]. This novel approach has been used for the preparation of nanocomposites by which nanoparticle formation and cross-linking processes can be accomplished in one-pot by simply irradiating appropriate formulations and demonstrate the nanoparticles are homogenously distributed in the network without macroscopic agglomeration. In this method, photo-induced processes involving reduction of metal salts to NPs and polymerization of difunctional monomers to cross-linked polymeric matrix occur simultaneously (Scheme 1). It seemed appropriate to employ such simultaneous reactions in the preparation of biosensors which requires additionally encapsulation of an enzyme. As part of our continuous interest in the development of photosensitive systems for various synthetic applications, the present paper is devoted to in situ synthesis of poly(ethylene glycol) (PEG) hydrogels containing AuNPs and bioenzyme by taking advantage of two reactions, namely photoinduced electron transfer and polymerization processes. For the potential use of the hydrogels formed on the platinum surface as biosensing surface, electrochemical glucose biosensing was presented as a model system. GOx which is mostly applied for design of electrochemical enzymatic biosensors was also selected in our work as the model enzyme due to its stability and practical applicability [22]. Newly designed bionanocomposite matrix was obtained by simple one-step fabrication (approximately in $180 \mathrm{~s}$ ). This matrix provided a good contact between the active site of the enzyme and AuNPs inside the network facilitating an enhanced electron transfer. This behavior was evidenced by cyclic voltammetry where higher amperometric responses were obtained in comparison to the matrix in the absence of AuNPs.

\section{Experimental}

\subsection{Materials}

Gold (III) chloride hydrate (Fluka, $\geq 49 \% \mathrm{Au}$ ), poly(ethylene glycol) diacrylate (PEGDA) (Aldrich, 98\%, $\mathrm{M}_{\mathrm{n}}: \sim 575 \mathrm{~g} / \mathrm{mol}$ ) and DL-camphoroquinone (CQ; Acros, 99\%) were used as received. Glucose oxidase (GOx; $\beta$-D-glucose: oxygen 1-oxidoreductase, E.C 1.1.3.4, Type II-S: from Aspergillus niger, $21200 \mathrm{U} / \mathrm{g}$ solid, $2.36 \mathrm{~g}$ solid) and D-glucose were purchased from Sigma-Aldrich Chem. All other chemicals were analytical grade.

\subsection{Fabrication procedure for bionanocomposite matrix}

Polymerization of acrylate moieties of PEGDA and simultaneous reduction of gold ions to metallic gold on a platinum surface in the

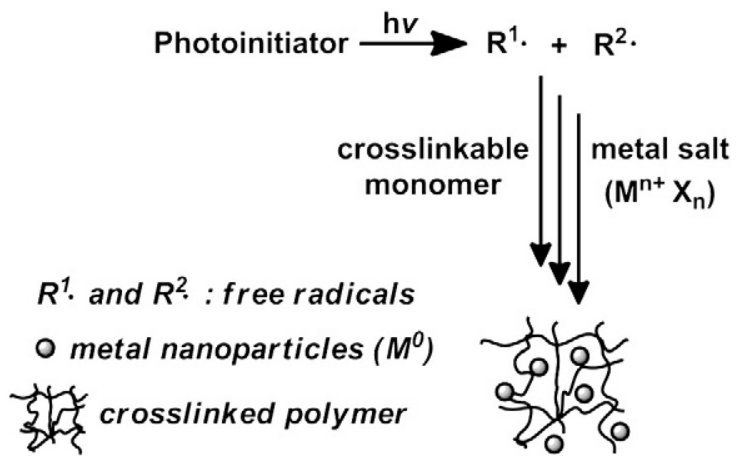

Scheme 1. Simultaneous photo-induced nanoparticle formation and cross-linking processes. presence of an enzyme (i.e. GOx) leads to formation of a simple biosensor for detection of analytes. As stated in introduction part, GOx is relatively stable and can be a model enzyme for biosensor applications. For these reasons, GOx was immobilized in a networked PEG by photo-induced free radical cross-linking of PEGDA.

A typical preparation of a biosensor is as follows. Stock solutions of each reagent were prepared in $0.1 \mathrm{M}, \mathrm{pH} 7.0$ potassium phosphate buffer and stored in an ice bath. $10 \mu \mathrm{l}$ of gold solution containing $2.0 \mathrm{mg} \mathrm{HAuCl}{ }_{4}$ and $10 \mu \mathrm{l}$ of enzyme solution containing $4.0 \mathrm{mg} \mathrm{GOx}$ were dissolved in $20 \mu \mathrm{l}$ PEGDA containing $5 \mathrm{wt} . \%$ of CQ. The solution was mixed well using Vortex just before polymerization. $4 \mu \mathrm{l}$ of the mixture was taken and placed uniformly onto the surface of a platinum electrode, which was polished by a polishing cloth with alumina of successively smaller particles $(1.0 \mu \mathrm{m}$ diameter $)$, rinsed with water and ultrasonicated in distilled water, respectively, prior to use for the modification. Then the electrode containing polymerization mixture was exposed to light for $3 \mathrm{~min}$ using a bluephase light source (supplied by ivoclar Vivadent Company) with an $8 \mathrm{~W}$ LED emitting at $430-490 \mathrm{~nm}$. The light intensity was $197 \mathrm{~mW} / \mathrm{cm}^{2}$ as measured by a Delta Ohm radiometer (model HD-9021). Upon irradiation, the yellow mixture became solid and semi-opaque purple in color.

\subsection{Instruments and measurements}

Amperometry and cyclic voltammetry experiments were performed on Palm Instruments (PalmSens, Houten, The Netherlands) with three electrode configuration where $\mathrm{Ag} / \mathrm{AgCl}$ (3 M KCl saturated with $\mathrm{AgCl}$ as an internal solution, Radiometer Analytical, REF321) and a Pt electrode (Metrohm, Switzerland) were used as the reference and counter electrodes, respectively and the modified Pt sheet $(0.5 \times 0.5 \mathrm{~cm})$ connected with the copper wire served as a working electrode.

All experiments were carried out at ambient conditions in a reaction cell containing $10 \mathrm{ml}$ working buffer solution (sodium acetate buffer; $50 \mathrm{mM}, \mathrm{pH}$ 4.0). After each run, the electrode was washed with distilled water and working buffer, respectively. The biosensor was initially equilibrated in buffer and then the substrate was added to the reaction medium and then, current response due to glucose addition was recorded. Chronoamperometric responses were registered as current signals $(\mu \mathrm{A})$ at $-0.7 \mathrm{~V}$ by following the oxygen consumption due to the enzymatic reaction in which glucose was oxidized to gluconic acid and hydrogen peroxide. Buffer was refreshed after each measurement. Enzyme electrodes were stored at the $4{ }^{\circ} \mathrm{C}$ when not in use. Stock glucose solutions were allowed to mutarotate for $24 \mathrm{~h}$ before use.

Cyclic voltammetry was carried out in the absence or presence of AuNPs in the matrix onto the Pt surface in sodium acetate buffer $(50 \mathrm{mM}, \mathrm{pH} 4.0)$ and $\left[\mathrm{Fe}(\mathrm{CN})_{6}\right]^{4-/ 3-}(10 \mathrm{mM})$ was used as a diffusional electron transferring mediator. The buffer solutions were deoxygenate with nitrogen bubbling for 30 min before voltammetric experiments.

Transmission electron microscopy (TEM) study was carried out on a FEI Tecnai G2 F30 instrument operating at an acceleration voltage of $100 \mathrm{kV}$. About $100 \mathrm{~nm}$ ultrathin TEM specimens were cut by cryoultramicrotome (EMUC6 + EMFC6, Leica) equipped with a diamond knife. The ultrathin samples were placed on copper grids for TEM analyses.

\subsection{Glucose analysis}

The proposed biocomposite matrix was tested for glucose biosensing in two different brands of non-alcoholic beverages (ice tea and cherry juice). No sample pretreatment was required and the samples were directly added to the reaction cell instead of the substrate and the current responses were registered and the glucose 
content was calculated from the calibration graph obtained by standard glucose solutions.

Additionally, HPLC with a refractive index detector (RID) controlled by a HP-Chemstation from Agilent (Karlsruhe, Germany) was used as the reference method for independent analysis of the glucose content. HPLC column (GL Sciences Inc. Inertsil $\mathrm{NH}_{2} 5.0 \mu \mathrm{m}$ (4.6 I. $\mathrm{D} \times 250 \mathrm{~mm}$ ), Japan) was used for the chromatographic separation of monosaccharides at $30^{\circ} \mathrm{C}$. Injection volume was $20 \mu$. The mobile phase was acetonitrile:water $(3: 1 \mathrm{w} / \mathrm{w})$ [34]. The flow rate was $1.0 \mathrm{ml} / \mathrm{min}$. Initially, standard curve for glucose was plotted $(0.5-$ $5.0 \mathrm{mg} / \mathrm{ml}$ for glucose). After dilution with mobile phase and filtration through membrane filter (pore size: $0.20 \mu \mathrm{M}$ ) samples were applied to the column and then glucose levels were calculated using calibration plot.

\section{Results and discussion}

The combination and formulation of synthetic and natural polymers with NPs and biomolecules synergistically allows combining advantageous chemical, physical, and biological properties to produce nanocomposite hydrogels that can be utilized in various bioapplications. On the other hand, macroscopic hydrogel matrices are advantageous materials for nanoparticle synthesis because they prevent aggregation and diffusion of the nanoparticles during synthesis [1]. In our case, a hydrogel matrix was also hosted for GOx during the synthesis of AuNPs and resulted bionanocomposite that was covered on the Pt surface was applied for the electrochemical glucose biosensing as the model study. The preparation process of the bionanocomposite is depicted in Scheme 2. In this process camphoroquinone (CQ) was deliberately selected as the photoinitiator so as to prevent any direct absorption by the components of the formulation since it absorbs the light at the visible range. Upon irradiation CQ forms both initiating and reducing radicals by hydrogen abstraction reaction.

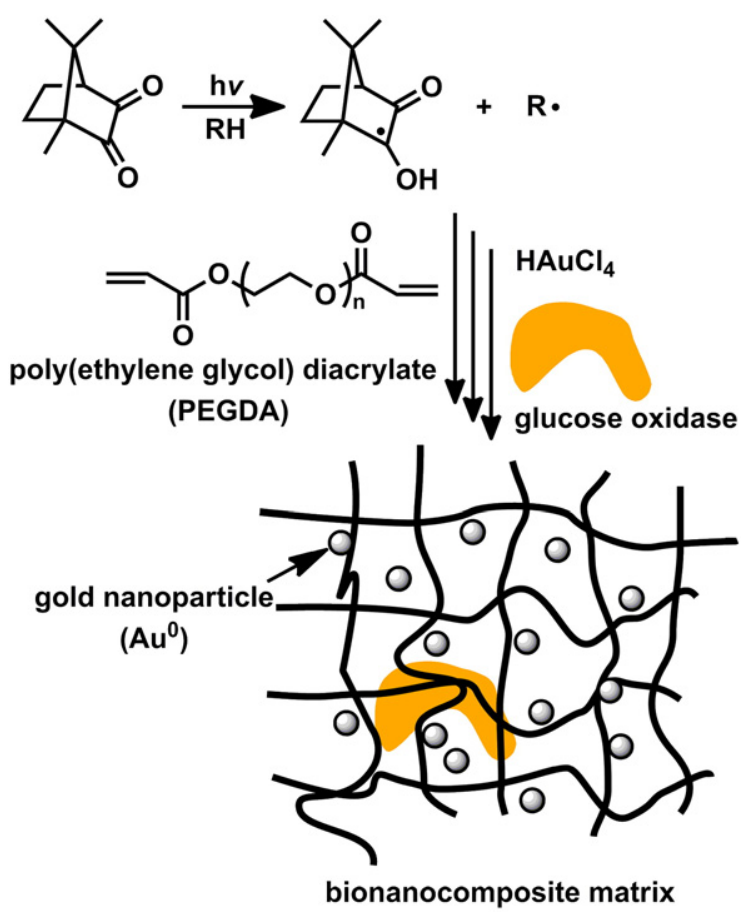

RH: hydrogen donor (monomer or solvent)

Scheme 2. Synthesis of gold-PEG nanocomposite containing GOx by simultaneous polymerization and metal ion reduction processes induced by light.
The presence of AuNPs in the hydrogel matrices with and without biomolecule was visualized by transmission electron microscopy (TEM). Representative TEM images of samples containing AuNPs and the size distribution of the NPs are shown in Fig. 1. In the absence of a biomolecule, the particle size is ranged from 2 to $5 \mathrm{~nm}$ and nanoparticles are uniformly distributed in the sample without significant macroscopic aggregation (Fig. 1A). In the case of sample with biomolecules, the AuNP dimensions are much bigger and ranges from 4 to $20 \mathrm{~nm}$ having a wide particle size distribution (Fig. 1B). Obviously, some aggregations of the NPs were noted in the matrix with the enzyme. This might be due to the possible adsorbtion of AuNPs to the enzyme without reducing its activity as previously reported [35]. It is also known that the peripheral protein layer could not be imaged due to the low electron resistance of protein molecules in TEM examination [36], hence the presence of the enzyme was not visualized in Fig. 1(B). Thus, NPs present in close proximity facilitated by protein molecules may agglomerate to form NPs with larger dimensions.

Cyclic voltammetry $(\mathrm{CV})$ of $\left[\mathrm{Fe}(\mathrm{CN})_{6}\right]^{4-/ 3-}$ is a valuable and convenient tool for testing electrochemical behavior of the enzyme electrode in which electron transfer properties between enzyme redox sites and the electrodes can be identified [37]. Fig. 2 shows cyclic voltammograms of the Pt electrodes modified with the biomatrices without (A) and with AuNPs (B) in the presence of [Fe $\left.(\mathrm{CN})_{6}\right]^{4-/ 3-}$ in working buffer solution (sodium acetate, $\mathrm{pH} 4.0$, $50 \mathrm{mM}$ ) at $50 \mathrm{mV} / \mathrm{s}$ scan rate. As can be seen from the figure, the modification of the electrode surface with AuNP during the gel formation step, has resulted in a positive catalytic effect on the oxidation $\left[\mathrm{Fe}(\mathrm{CN})_{6}\right]^{4-}$ ion. While, almost no well-defined peaks with lower peak current $(71.6 \mu \mathrm{A})$ were observed when no AuNP existed in the composite matrix, the apparent shift in the peak potential (from $380 \mathrm{mV}$ to $292 \mathrm{mV}$ ) was accompanied by the increase in peak current $(108 \mu \mathrm{A})$ due to AuNPs indicating enhanced reaction kinetics as already reported for the other types of AuNP modified GOx biosensors [38]. AuNPs were also reported to be used as a very efficient redox mediator suitable for biosensor design [28]. On the other hand, similar effects showing the accelerated electron transfer properties were observed in one of the previous study which revealed the spectrophotometric evaluation of AuNPs as redox mediator for GOx. In that work it was shown that when the efficient contact between AuNP and the active site of the enzyme was provided, AuNPs that are competing with the redox mediator used in the reaction are quickly re-oxidizing GOx and then transfer the electrons to the other acceptor molecules. Hence, the synergic effect of AuNP and the redox mediator can provide higher bioelectrocatalytic activity [22]. It was also reported that AuNPs with GOx provides a microenvironment similar to that of the redox proteins in native system that allows for protein molecules' more freedom in orientation thereby reducing the insulating effect of the protein shell for the direct electron transfer (DET) [28].

The CVs of the biosensing systems with and without AuNPs at different scan rates were shown in Figs. 3 and 4, respectively. It was also observed that in comparison to the behavior of NP modified electrode, the shift in the anodic and cathodic peak potentials by increasing the scan rate for the biocomposite without AuNP indicates a quasi-reversible electrode process so that an apparent contribution was observed by the presence of AuNPs as expected. In other words, the difference in the anodic and cathodic peak potentials were calculated as 141 and $267 \mathrm{mV}$, respectively in the presence and absence of AuNPs into the structure at $25 \mathrm{mV} / \mathrm{s}$ scan rate. This difference clearly demonstrates that the presence of AuNPs improves the reaction kinetics through tiny bridges for electron transfer and therefore the electrode process can be concluded as approaching the reversibility. Our findings were also well agreed with the previous work in which GOx was immobilized on AuNPs, which had selfassembled on $\mathrm{Au}$ electrode modified with thiol-containing 3D network of silica gel. In that system it was stated that the higher 
A

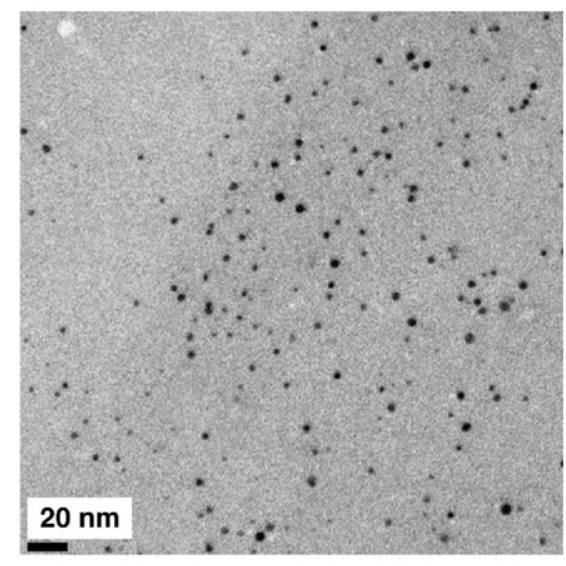

B

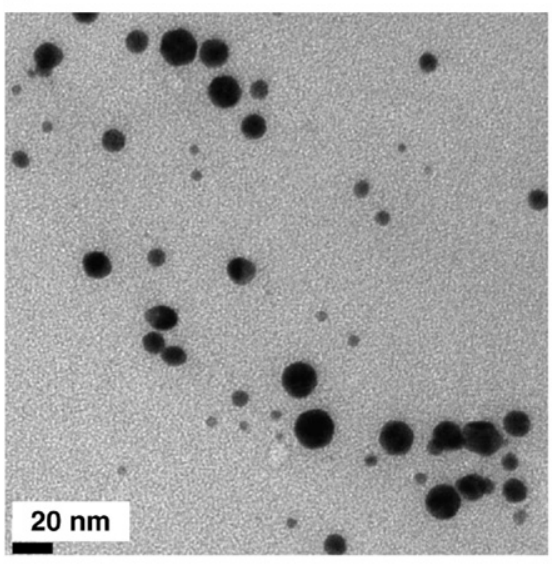

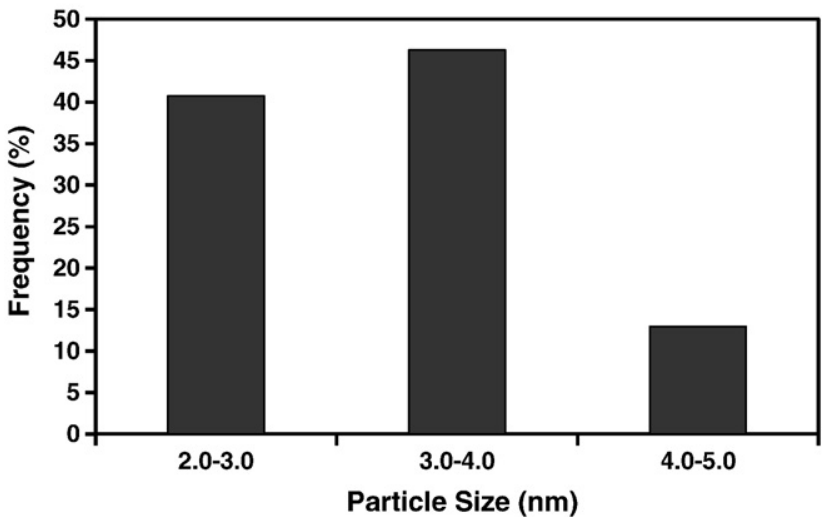

Particle Size (nm)

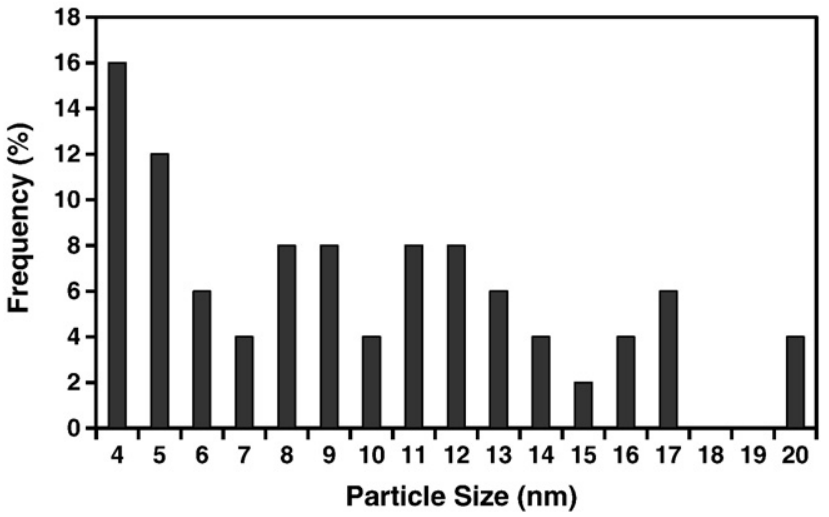

Fig. 1. Representative TEM images and corresponding size distributions of the AuNPs in hydrogel matrices without enzyme (A) and with enzyme (B).

electrically wired active enzyme might be caused by the formation of tiny conducting centers because of the AuNPs between redox center of the enzyme and the electrode surface that facilitates the electron transfer by reducing the energy barrier [37]. On the basis of the above information, the overall biosensing redox process by using PEG-based hydrogel containing both AuNPs and GOx is schematically presented in Scheme 3.

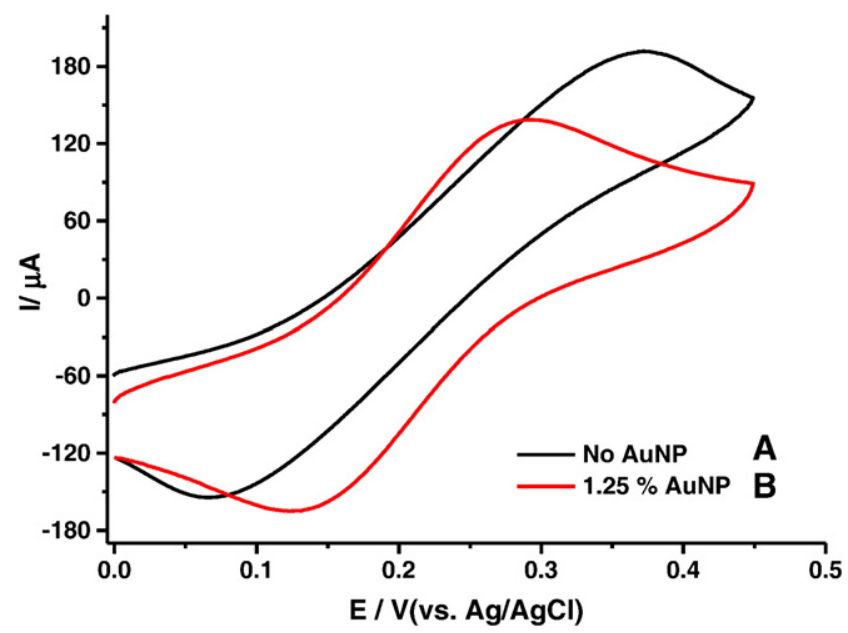

Fig. 2. Cyclic voltammograms of GOx electrodes: (A) AuNP-free electrode and (B) AuNPs-modified electrode (in $\mathrm{pH} 4.0,50 \mathrm{mM}$ sodium acetate buffer; $25^{\circ} \mathrm{C}$; electrode composition: 17 Unit GOx and 1.25\% AuNP).

\subsection{Effect of some parameters on the biosensor response}

Prior to investigation of response characteristics showing the performance of the proposed biosensing system, some parameters important in the optimization studies such as optimum $\mathrm{pH}$, enzyme loading and AuNP amount were examined by the monitoring of consumed oxygen through the biocatalytic reaction in the presence of

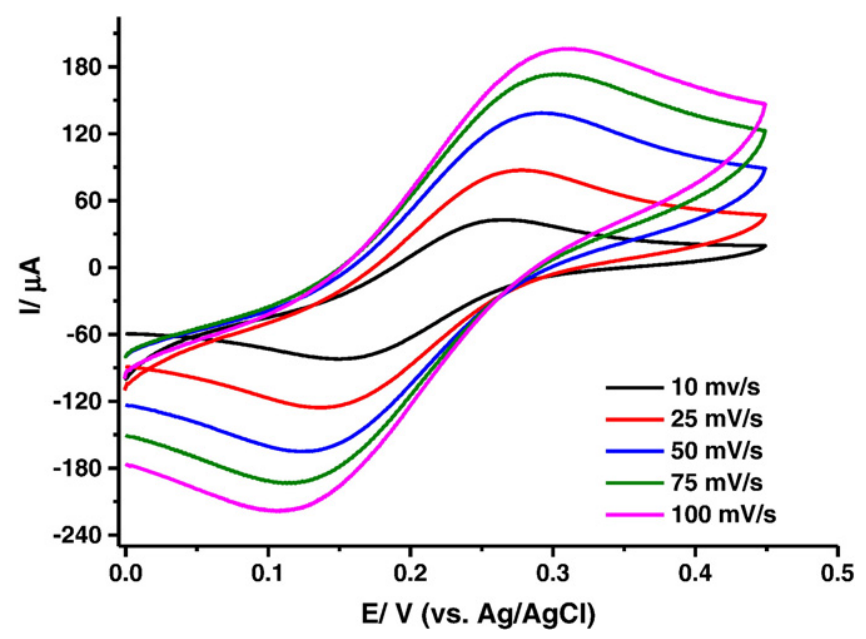

Fig. 3. Cyclic voltammograms of AuNP/GOx electrodes at different scan rates (in pH 4.0, $50 \mathrm{mM}$ sodium acetate buffer; $25^{\circ} \mathrm{C}$; electrode composition: 17 Unit GOx and $1.25 \%$ AuNP; $\left.\left.\mathrm{Fe}(\mathrm{CN})_{6}\right]^{4-/ 3-}: 10 \mathrm{mM}\right)$. 


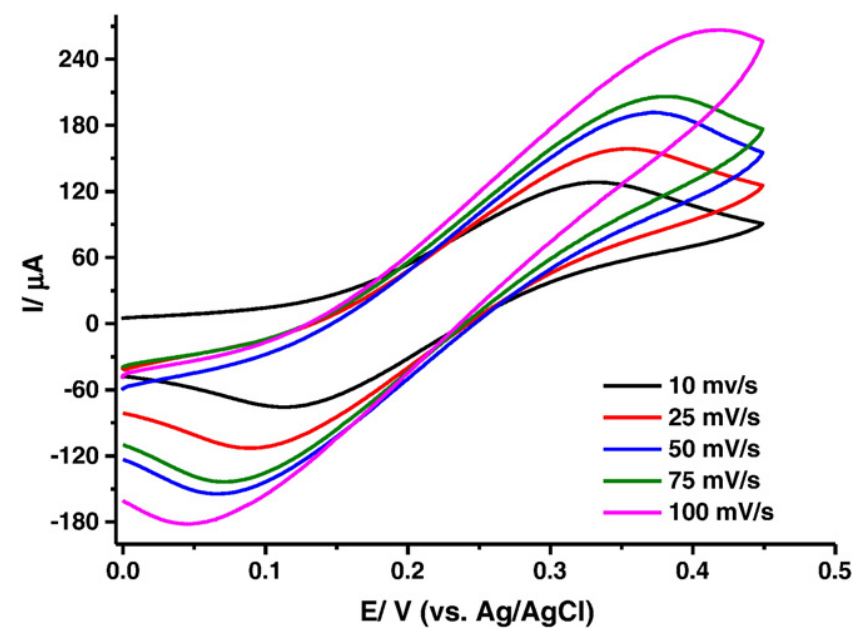

Fig. 4. Cyclic voltammogrames of GOx electrodes without AuNPs at different scan rates (in $\mathrm{pH}$ 4.0, $50 \mathrm{mM}$ sodium acetate buffer; $25^{\circ} \mathrm{C}$; electrode composition: $17 \mathrm{U} \mathrm{GOx}$ and $1.25 \%$ AuNP; $\left.\left.\mathrm{Fe}(\mathrm{CN})_{6}\right]^{4-/ 3-}: 10 \mathrm{mM}\right)$.

glucose at $-0.7 \mathrm{~V}$ vs $\mathrm{Ag} / \mathrm{AgCl}$. Examination of the $\mathrm{pH}$ value on the performance of the biosensor is of great importance as the biocatalytic activity of the enzymes strongly depends on this value. The current responses of the proposed biosensor (AuNP/GOx biocomposite) to glucose $(1.0 \mathrm{mM})$ were measured at different $\mathrm{pHs}$ (3.5-5.5) by using $50 \mathrm{mM}$ of sodium acetate buffer (Fig. 5). It can be seen that the current response reached its maximum at $\mathrm{pH} 4.0$, and then decreased at higher pHs. For the free GOx maximum activity was previously reported as pH $5.6[39,40]$. Additionally, different $\mathrm{pH}$ optimum values for GOx biosensors depending on the immobilization matrices and procedures used were obtained in previous studies [21]. In our case, the shift to the more acidic region in $\mathrm{pH}$ optimum in comparing to the free enzyme could be explained by the fact that pI value for GOx is 4.2 and at lower pHs it has rather positively charged so that the electrostatic forces between AuNPs and GOx might be more attractive in compared with the higher pHs than 4.2. Hence this effect caused an additional contribution to the possible contacts due to the cysteine
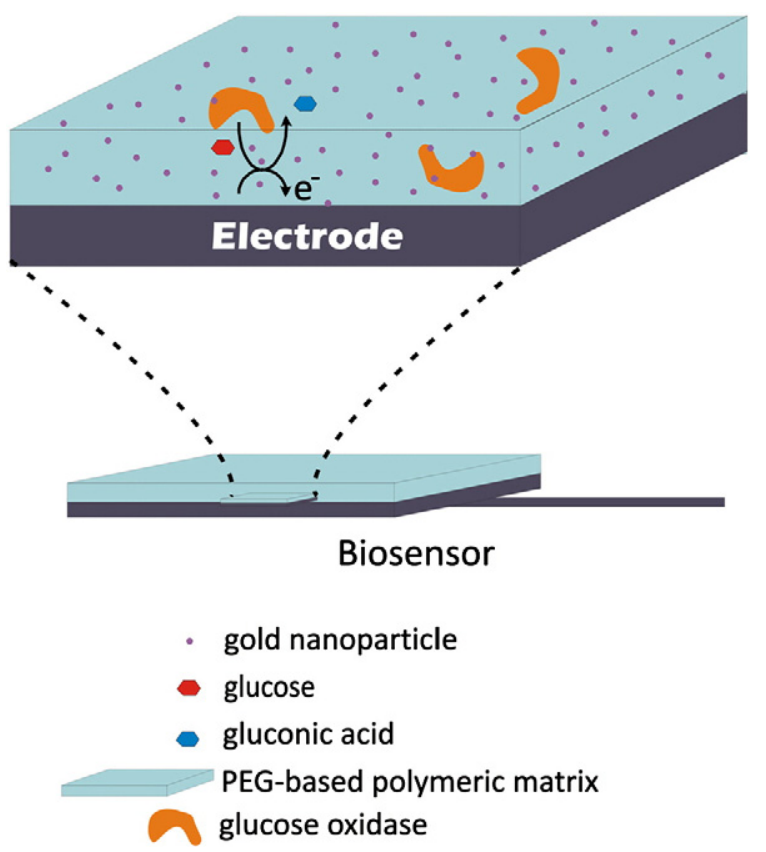

Scheme 3. Schematic representation of nanocomposite biosensing system on the platinum surface.

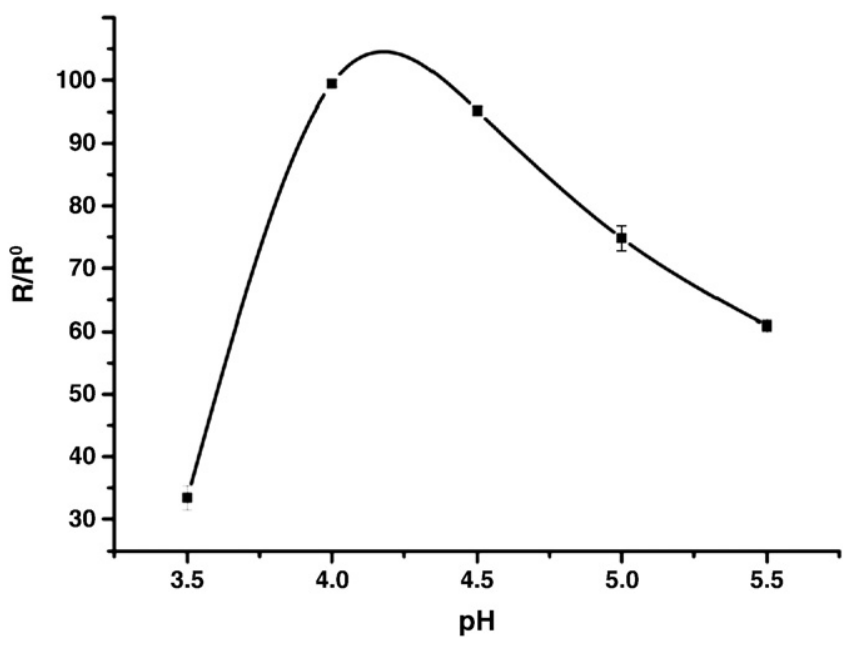

Fig. 5. Response of AuNP/GOx electrode as a function of $\mathrm{pH}$ in the presence of glucose (1.0 mM); pH 3.5-5.5; $50 \mathrm{mM}$ sodium acetate buffer, $25^{\circ} \mathrm{C} ;-0.7 \mathrm{~V} ; R$ : current, $R_{0}$ : maximum current). Error bars show standard deviation of 3 or 4 measurements.

residues of GOx that leads the formation of GOx/AuNP complex [22]. A drop observing at $\mathrm{pH} 3.5$ might be explained by the possible denaturation in the protein structure. Since maximum activity was observed at $\mathrm{pH} 4.0$ other experimental steps were conducted by this value.

The effect of enzyme loading was tested by biocomposite sensing system containing different enzyme amounts and the current responses vs glucose concentration were given in Fig. 6. As can be seen from the curves better linearity with high sensitivity according to the slope of the curve was observed by 17.0 Unit which equals $0.8 \mathrm{mg}$ protein and the linearity was defined by the equation $y=0.403 x$ $+0.968\left(R^{2}=0.995\right)$. In the case of 13.6 Unit GOx activity (which equals $0.64 \mathrm{mg}$ protein), the calibration graph was constructed in the same concentration range with an equation of $y=0.235 x+2.872$ $\left(R^{2}=0.986\right)$. Since higher enzyme amounts caused the improper matrix formation, for the further experimental steps biocomposite matrix including 17.0 Unit GOx activity was used.

As well as the effect of NP amount was concerned, when $1.25 \%$ AuNP content was used, maximum current responses were obtained for the biosensor containing 17.0 Unit enzyme activity (Fig. 7). Higher $\mathrm{NP}$ amounts caused decrease in the responses and this might be due to the diffusion problem for the substrate as well as limited orientation for the enzyme that diminished the biocatalytic activity. Hence, the

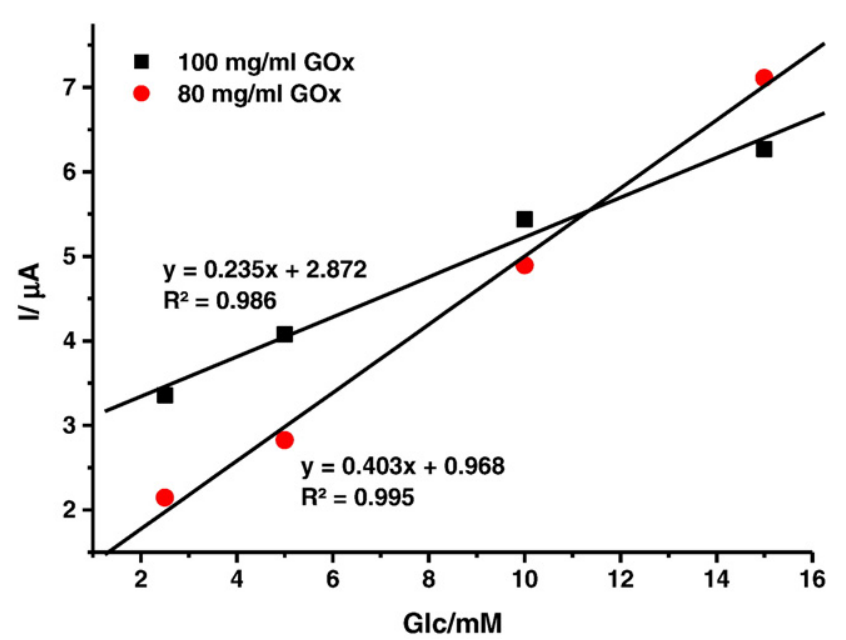

Fig. 6. Effect of enzyme loading (in $\mathrm{pH} 4.0,50 \mathrm{mM}$ sodium acetate buffer; $25^{\circ} \mathrm{C}$; $-0.7 \mathrm{~V}$; 5.0\% AuNP; 13.6 U GOx, 17 Unit GOx). 


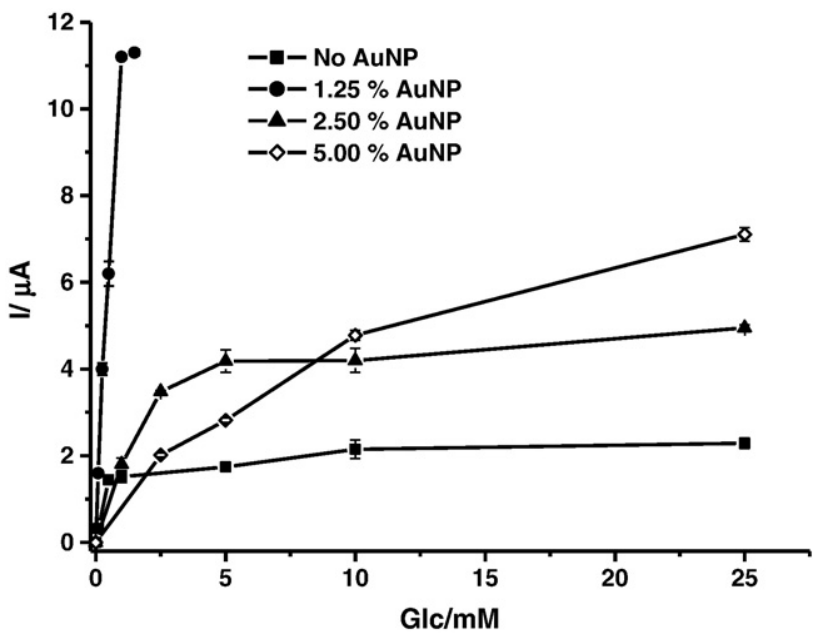

Fig. 7. Effect of AuNP amount (in pH 4.0, $50 \mathrm{mM}$ sodium acetate buffer; $25^{\circ} \mathrm{C}$; $-0.7 \mathrm{~V}$; 17 U GOx; Without AuNP, $1.25 \%$ AuNP, $\triangle 2.5 \%$ AuNP, $\diamond 5 \%$ AuNP). Error bars show standard deviation of 3 or 4 measurements.

biocomposite matrix (with 17.0 Unit GOx and 1.25\% AuNP content) showing highest activity was used for examination of response characteristics.

\subsection{Response characteristics}

The analytical characteristics of the proposed biosensor (AuNP/ GOx) were examined by the monitoring chronoamperometric response at $-0.7 \mathrm{~V}$ under optimized conditions at sodium acetate buffer ( $50 \mathrm{mM}, \mathrm{pH} 4.0$ ) and the linear graph was obtained in the range of $0.1-1.0 \mathrm{mM}$ for the glucose substrate by the equation of $y=10.893 x+0.569\left(R^{2}=0.988, y\right.$ and $x$ shows concentration in $\mathrm{mM}$ and current in $\mu \mathrm{A}$, respectively). At higher glucose concentrations, deviation from the linearity and lower current signals were observed. This might be explained by the product $\left(\mathrm{H}_{2} \mathrm{O}_{2}\right)$ inhibition to the enzyme [41]. It is known that in the enzymatic oxidation of glucose by using oxygen as a co-substrate, the byproduct hydrogen peroxide produced with the desired product gluconic acid has been known to exert an inhibitory effect on the catalytic activity of GOx [42]. In our case, at higher substrate concentrations, accumulated $\mathrm{H}_{2} \mathrm{O}_{2}$ through the enzymatic reaction into the polymeric network exhibited inhibitory effect as previously reported for both free and immobilized GOx [42]. Another fact effected that the linear range could be diffusion problem for the oxygen due to the excess peroxide accumulation in the hydrogel matrix. Response signal was obtained in $60 \mathrm{~s}$ and a typical steady-state current-time response graph was shown in Fig. 8.

The detection limit (LOD) of the biosensor was determined to be $0.06 \mathrm{mM}$ at a signal to noise ratio of 3. When AuNP were not involved in the structure, the linear scale was observed in the range of $0.1-$ $0.5 \mathrm{mM}$ and the linear graph were defined by the equation of $y=2.733 x-0.006\left(R^{2}=0.997, y\right.$ and $x$ shows concentration in $\mathrm{mM}$ and current in $\mu \mathrm{A}$, respectively). It is clear that the higher current signals was due to the accelerated electron transfer in the presence of AuNPs toward electrode surface as stated before and supported by the data obtained from the cyclic voltammetry experiments by using diffusional redox mediator.

Stability and reproducibility are important parameters for the evaluation of the sensing system. As far as operational stability was concerned, the proposed sensor was kept in the reaction cell containing working buffer and $25 \%$ decrease of the current response was observed after 3 hours and in this period 14 measurements were done. The reproducibility of the biosensor was examined to $0.5 \mathrm{mM}$ glucose solution. According to the results of 6 replicates of trials

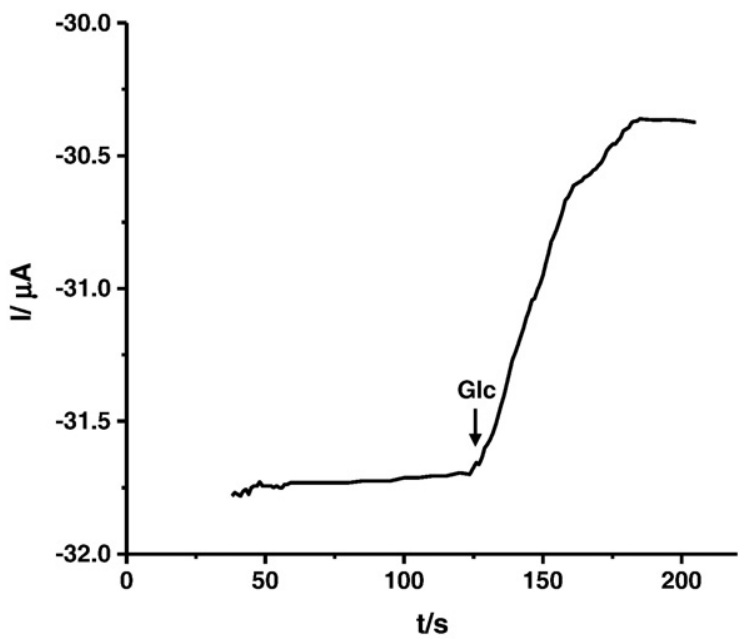

Fig. 8. A typical steady-state current-time response graph under optimized conditions.

variation coefficient (c.v) was calculated as 3.8\%. The electrode-toelectrode reproducibility was also tested between 3 different electrodes for the same conditions mentioned before and the c.v was calculated to be $4.3 \%$. Good reproducibility might be explained by the presence of good and the stable contact between NPs and the enzyme which was provided by properly optimized hydrogel structure.

\subsection{Glucose analysis in samples}

The prepared AuNP/GOx biosensor was used in the glucose analysis in two different commercial beverages. For the glucose biosensing, sample pretreatment was not required and the sample was directly applied to the reaction cell containing sodium acetate buffer ( $50 \mathrm{mM}, \mathrm{pH} 4.0$ ) instead of substrate. Glucose amount was calculated by using linear graph (defined by the equation of $y=10.893 x+0.569$, as described before). The results were compared with those obtained with HPLC method. Glucose standard curve obtained from the HPLC was defined by the equation of $y=123507 x$ $-30654\left(R^{2}=0.994\right)$, in which $x$ and $y$ show glucose concentration in $\mathrm{mg} / \mathrm{ml}$ and peak area; nRIU, in the range of $0.5-5.0 \mathrm{mg} / \mathrm{ml}$ glucose. The comparison of the results obtained from both HPLC and AuNP/ GOx biosensor was shown in Table 1. Data were presented as the average of 3 or 4 replicates of trials \pm S.D. According to data it can be said that the use of AuNPs/GOx biosensor provided very similar results with the HPLC data which indicated the analysis without any sample matrix effect.

\section{Conclusion}

In conclusion, we describe that a simple and attractive method allows for simultaneous AuNP and network formation in the presence of bioactive molecule on the Pt surface that served as a biosensing platform.

The resulted polymer network was tested as enzyme immobilizing device for its use in electrochemical biosensors. The method used in the biosensor construction could be a good alternative on thick film

Table 1

Comparison of HPLC and AuNP/GOx electrode results.

\begin{tabular}{lllc}
\hline Sample & {$[\mathrm{Glc}](\mathrm{g} / 100 \mathrm{ml})$} & \multirow{2}{*}{ Recovery \% } \\
\cline { 2 - 3 } & AuNP/GOx biosensor ${ }^{\mathrm{a}}$ & HPLC $^{\mathrm{a}}$ & \\
\hline Ice tea & $3.63 \pm 0.038$ & $3.45 \pm 0.022$ & 105 \\
Cherry juice & $4.75 \pm 0.166$ & $5.18 \pm 0.039$ & 92 \\
\hline
\end{tabular}

a Data were given as the average \pm S.D ( $n$ : 3 or 4 ). 
screen printing and ink jet printing techniques for the production of cost-effective, single use disposable biosensors as a platform technology. On the other hand, the facilitated transfer of the electrons released in the enzymatic reaction from the catalytic site to the platinum electrode surface was observed by the presence of AuNPs. The combination of small size AuNPs with the redox enzyme inside the polymeric material yielded a nanobiocomposite structure with unique and versatile properties and can be a useful candidate as biocatalytic nanoscale-device or nanorectors based on glucose oxidation reaction in various biotechnological applications such as biofuel cell design as well as biological analysis. It can be concluded that one-step nanocomposite fabrication method that could be successfully applied for the entrapment of drugs and various biomacromolecules inside hydrogels structures opens new possibilities in fields like controlled drug release and fabrication of promising biosensor devices.

\section{Acknowledgements}

This work was supported by Istanbul Technical University (ITU) and the Ege University Research Grants. M. U. Kahveci thanks to TUBITAK for financial support as a graduate scholarship. Prof. N. Ertas is acknowledged for the fruitful discussions on the electrochemical data. The State Planning Organization of Turkey (DPT) is acknowledged for the support of UNAM-Institute of Materials Science and Nanotechnology through the National Nanotechnology Research Center Project. H. Deniz and M. Guler are also acknowledged for helping TEM imaging and sample preparation for TEM, respectively.

\section{References}

[1] P. Schexnailder, G. Schmidt, Nanocomposite polymer hydrogels, Colloid Polym. Sci. 287 (2009) 1-11.

[2] D. Odaci, B.N. Gacal, B. Gacal, S. Timur, Y. Yagci, Fluorescence sensing of glucose using glucose oxidase modified by pva-pyrene prepared via "click" chemistry, Biomacromolecules 10 (2009) 2928-2934.

[3] F.R.R. Teles, L.P. Fonseca, Applications of polymers for biomolecule immobilization in electrochemical biosensors, Mat. Sci. Eng. C- Bio. S. 28 (2008) 1530-1543.

[4] D. Odaci, A. Telefoncu, S. Timur, Pyranose oxidase biosensor based on carbon nanotube (CNT) modified carbon paste electrodes, Sensor. Actuat. B Chem. 132 (2008) 159-165.

[5] L.C. Lora Huang, H.C. Chang, Adsorption and immobilization of cytochrome $\mathrm{C}$ on nanodiamonds, Langmuir 20 (2004) 5879-5884

[6] S. Tuncagil, D. Odaci, S. Varis, S. Timur, L. Toppare, Electrochemical polymerization of 1-(4-nitrophenyl)-2, 5-di(2-thienyl)-1 H-pyrrole as a novel immobilization platform for microbial sensing, Bioelectrochemistry 76 (2009) 169-174.

[7] S. Timur, U. Anik, D. Odaci, L. Gorton, Of a microbial biosensor based on carbon nanotube (CNT) modified electrodes, Electrochem. Commun. 9 (2007) 1810-1815.

[8] S.A. Yamanaka, D.H. Charych, D.A. Loy, D.Y. Sasaki, Solid phase immobilization of optically responsive liposomes in sol-gel materials for chemical and biological sensing, Langmuir 13 (1997) 5049-5053.

[9] E. Williams, M.I. Pividori, A. Merkoçi, R.J. Forster, S. Alegret, Rapid electrochemical genosensor assay using a streptavidin carbon-polymer biocomposite electrode, Biosens. Bioelectron. 19 (2003) 165-175.

[10] S.Q. Hu, J.W. Xie, Q.H. Xu, K.T. Rong, G.L. Shen, R.Q. Yu, A label-free electrochemical immunosensor based on gold nanoparticles for detection of paraoxon, Talanta 61 (2003) 769-777

[11] C. Ozdemir, F. Yeni, D. Odaci, S. Timur, Electrochemical glucose biosensing by pyranose oxidase Immobilized in gold nanoparticle-polyaniline/ $\mathrm{AgCl} / g$ elatin nanocomposite matrix, Food Chem. 119 (2010) 380-385.

[12] H. Yang, S.Y. Fung, M. Pritzker, P. Chen, Ionic-complementary peptide matrix for enzyme immobilization and biomolecular sensing, Langmuir 25 (2009) 7773-7777.

[13] A. Cirpan, S. Alkan, L. Toppare, I. Cianga, Y. Yagci, Immobilization of cholesterol oxidase in conducting copolymer of thiophene-3-yl acetic acid cholesteryl ester with pyrrole, Des. Monomers Polym. 6 (2003) 237-243.

[14] S. Kiralp, L. Toppare, Y. Yagci, Immobilization of polyphenol oxidase in conducting copolymers and determination of phenolic compounds in wines with enzyme electrodes, Int. J. Biol. Macromol. 33 (2003) 37-41.
[15] A. Arslan, S. Kiralp, L. Toppare, Y. Yagci, Immobilization of tyrosinase in polysiloxane/polypyrrole copolymer matrices, Int. J. Biol. Macromol. 35 (2005) 163-167.

[16] H.B. Yildiz, S. Kiralp, L. Toppare, Y. Yagci, Immobilization of glucose oxidase in conducting graft copolymers and determination of glucose amount in orange juices with enzyme electrodes, Int. J. Biol. Macromol. 37 (2005) 174-178.

[17] A.E. Boyukbayram, S. Kiralp, L. Toppare, Y. Yagci, Preparation of biosensors by immobilization of polyphenol oxidase in conducting copolymers and their use in determination of phenolic compounds in red wine, Bioelectrochemistry 69 (2006) 164-171.

[18] D. Odaci, S. Timur, A. Telefoncu, Bacterial sensors based on chitosan matrices, Sensor. Actuat. B-Chem. 134 (2008) 89-94.

[19] S. Timur, Y. Yigzaw, L. Gorton, Electrical wiring of pyranose oxidase with osmium redox polymers, Sensor. Actuat. B Chem. 113 (2006) 684-691.

[20] Ü.A. Kirgoz, S. Timur, J. Wang, A. Telefoncu, Xanthine oxidase modified glassy carbon paste electrode, Electrochem. Commun. 6 (2004) 913-916.

[21] X.L. Luo, J.J. Xu, Y. Du, H.Y. Chen, A glucose biosensor based on chitosan-glucose oxidase-gold nanoparticles biocomposite formed by one-step electrodeposition, Anal. Biochem. 334 (2004) 284-289.

[22] A. Ramanavicius, A. Kausaite, A. Ramanaviciene, In 18th Eurosensors Conference, Italy, 2004.

[23] I. Willner, B. Willner, E. Katz, In 18th International Symposium on Bioelectrochemistry and Bioenergetics/3rd Spring Meeting of the International-Society-ofElectrochemistry, Portugal, 2005.

[24] M.C. Daniel, D. Astruc, Gold nanoparticles: assembly, supramolecular chemistry, quantum-size related properties, and applications towards biology, catalysis and nanotechnology, Chem. Rev. 104 (2004) 293-346.

[25] J. Wang, Carbon-nanotube based electrochemical biosensors: a. review, Electroanal 17 (2005) 7-14.

[26] S.X. Zhang, N. Wang, H.J. Yu, Y.M. Niu, C.Q. Sun, Covalent attachment of glucose oxidase to an Au electrode modified with gold nanoparticles for use as glucose biosensor, Bioelectrochemistry 67 (2005) 15-22.

[27] M. Pumera, J. Wang, E. Grushka, R. Polsky, Gold nanoparticle-enhanced microchip capillary electrophoresis, Anal. Chem. 73 (2001) 5625-5628.

[28] Y. Xiao, F. Patolsky, E. Katz, J.F. Hainfeld, I. Willner, 'Plugging into enzymes': nanowiring of redox-enzymes by a gold nanoparticle, Science 299 (2003) 1877-1881.

[29] M. Sangermano, Y. Yagci, G. Rizza, In situ synthesis of silver-epoxy nanocomposites by photoinduced electron transfer and cationic polymerization processes, Macromolecules 40 (2007) 8827-8829.

[30] Y. Yagci, M. Sangermano, G. Rizza, A visible light photochemical route to silverepoxy nanocomposites by simultaneous polymerization-reduction approach, Polymer 49 (2008) 5195-5198.

[31] Y. Yagci, M. Sangermano, G. Rizza, Synthesis and characterization of gold-epoxy nanocomposites by visible light photoinduced electron transfer and cationic polymerization processes, Macromolecules 41 (2008) 7268-7270.

[32] Y. Yagci, M. Sangermano, G. Rizza, In situ synthesis of gold-cross-linked poly (ethylene glycol) nanocomposites by photoinduced electron transfer and free radical polymerization processes, Chem. Commun. (2008) 2771-2773.

[33] M. Uygun, M.U. Kahveci, D. Odaci, S. Timur, Y. Yagci, Antibacterial acrylamide hydrogels containing silver nanoparticles by simultaneous photoinduced free radical polymerization and electron transfer processes, Macromol. Chem. Physic. 210 (2009) 1867-1875.

[34] A.M. Wilson, T.M. Work, A.A. Bushway, R.J. Bushway, HPLC determination of fructose, glucose and sucrose in potatoes, J. Food Sci. 46 (1981) 300-301.

[35] M. Bendayan, Colloid Gold: Principles, Methods, and Applications, Academic Press, San Diego, 1989.

[36] D.X. Li, Q. He, Y. Cui, L. Duan, J.B. Li, Immobilization of glucose oxidase onto gold nanoparticles with enhanced thermostability, Biochem. Bioph. Res. Co. 355 (2007) 488-493.

[37] S.X. Zhang, N. Wang, Y.M. Niu, C.Q. Sun, Immobilization of glucose oxidase on gold nanoparticles modified Au electrode for the construction of biosensor, Sensor. Actuat. B Chem. 109 (2005) 367-374.

[38] Q.L. Sheng, Y. Shen, H.F. Zhang J.B. Zheng, Direct electrochemistry of glucose oxidase immobilized on chitosan-gold nanoparticle composite film on glassy carbon electrodes and its biosensing application, Chin. J. Chem. 26 (2008) 1244-1250.

[39] H.J. Bright, M. Appleby, The pH dependence of the individual steps in the glucose oxidase reaction, J. Biol. Chem. 244 (1969) 3625-3634.

[40] L. Li, Q.L. Sheng, J.B. Zheng, H.F. Zhang, Facile and controllable preparation of glucose biosensor based on Prussian blue nanoparticles hybrid composites, Bioelectrochemistry 74 (2008) 170-175.

[41] J. Bao, K. Furumoto, M. Yoshimoto, K. Fukunaga, K. Nakao, Competitive inhibition by hydrogen peroxide produced in glucose oxidation catalyzed by glucose oxidase, Biochem. Eng. J. 13 (2003) 69-72.

[42] M. Yoshimoto, Y. Miyazaki, M. Sato, K. Fukunaga, R. Kuboi, K. Nakao, Mechanism for high stability of liposomal glucose oxidase to inhibitor hydrogen peroxide produced in prolonged glucose oxidation, Bioconjugate Chem. 15 (2004) 1055-1061. 